\title{
(4) Dietary Treatment in Kidney Diseases
}

\author{
Kenzo Oshima \\ Department of Internal Medicine, Nihon University School of Medicine
}

\begin{abstract}
Recent advances in the study on renal physiology have brought the changes in the principal consideration in dietary treatment. Classic diet has been arranged for the purpose to save the work of the kidney, while the hypothesis of that such diet would reduce the energy in the transport system in tubular cells was denied. Principle of modern dietary treatment should be based on the metabolic point of view, which would be disturbed in many phases in kidney diseases. Analysis of balance study on water, sodium, potassium and nitrogen, and the observation on the effect of diet on it, will offer the basic knowledge for the mode of the dietary treatment in kidney diseases. Furthermore, studies of the influence of fat intake on the serum lipoprotein and renal function will be necessary, particularly in the treatment of nephrotic syndrome.
\end{abstract}

\section{Methods}

Balance studies were carried out according to the following modes, in the cases with acute, chronic glomerulonephritis, chronic renal failure and nephrotic syndrome. In the sodium balance study, $204 \mathrm{~m}$ Eq. per day of sodium was given during 2 weeks, and it was restricted to $44 \mathrm{~m} \mathrm{Eq}$. following 2 weeks. In the potassium balance study, $70 \mathrm{~m} \mathrm{Eq}$. of $\mathrm{K}$ was given for first 2 weeks, and it was restricted to $39.2 \mathrm{~m} \mathrm{Eq}$. for next 2 weeks. GFR was measured by creatinine 24 hours clearance. Low density and high density lipoproteins were measured by ultra centrifuge. In the microscopic observation of the kindey of lanolin fed rabbits, HE and Sudan-III stains were applied.

\section{Results}

1) Remarkable positive Na-balance was observed in oliguric phase of acute glomerulonephritis, nephrotic syndrome and chronic renal failure during the sodium intake of $204 \mathrm{~m} \mathrm{Eq}$. per day, and it tended towards normal balance under the sodium restriction of $44 \mathrm{~m} \mathrm{Eq.} \mathrm{per} \mathrm{day.}$

2) Remarkable negative Na-balance was observed in cases with polyuric phase of chronic renal failure and pyelonephritis under restriction of sodium intake, and it tended towards normal balance under the usual diet containing 8-12 g. of $\mathrm{NaCl}$, accompanied with the clinical improvement, increase of serum $\mathrm{Na}, \mathrm{K}, \mathrm{Cl}$ levels and the creatinine clearance. 
3) Significant correlation between sodium excretion rate and urine volume was observed in cases with acute, chronic glomerulonephritis, pyelonephritis and chronic renal failure, while no correlation was observed between potassium excretion rate and urine volume.

4) Sodium restriction caused decrease of sodium excretion rate, while potassium excretion rate showed tendency to increase, indicating the possibility of sodium and potassium exchange in tubular cells.

5) Sodium restriction diet resulted in decrease of creatinine clearance, $12.4 \%$ on an average.

6) Sodium restriction or protein restriction exerted almost no effect upon acidbase balance in cases with chronic renal failure, while the amplitude of excretion rate of $\mathrm{CO}_{2}, \mathrm{NH}_{4}, \mathrm{H}^{+}$was limited under the load of ammonium chloride or sodium bicarbonate.

7) Two groups of hyperlipemia were observed in nephrotic syndrome; group A showed remarkable increase of both $S_{f 0-12}$ and $S_{f 12-400}$ lipoproteins, while group $B$ showed single increase of $\mathrm{S}_{\mathrm{f} 12-200}$ lipoprotein.

8) Fat intake (25 $\mathrm{g}$. butter at once) resulted in a marked decrease of RPF in cases with nephrotic syndrome, measured after 4 hours of ingestion.

9) The histologic findings of the kidney of lanolin fed rabbits, showed remarkable fat deposit and attendance of phagocytes in the interstitial cells, particularly in the zone of cortico-medullary border line.

\section{Conclusion}

Above mentioned observations lead to the following conclusion.

a) Strict restriction of sodium intake (usually under $0.5 \mathrm{~m}$ Eq. per day) should be kept in oliguric stage of acute glomerulonephritis. Potassium restriction (under $40 \mathrm{~m} \mathrm{Eq.} \mathrm{per} \mathrm{day)} \mathrm{and} \mathrm{protein} \mathrm{restriction} \mathrm{(under} 15 \mathrm{~g}$. per day) are also necessary. Water intake must be kept in 300-500 cc. plus urine volume.

b) Sodium and potassium restriction should be ceased when urine volume become increased, and protein restriction should be also receded.

c) High protein diet in nephrotic syndrome should be indicated, looking the levels of BUN on one hand, and the amount of excreted protein on the other hand, keeping in mind the standard dosage of $0.7 \mathrm{~g}$. per $\mathrm{Kg}$. plus amount of urine protein.

d) Saturated fatty acid and excess intake of carbohydrate are unfavorable to the high lipoproteinemia of nephrotic syndrome, resulting in the decrease of RPF.

e) The possibility of harmful effects of fat diet to the kidney tissue has been shown.

f) Protein restriction in cases with chronic renal failure should be arranged according to the follow up observation of $\mathrm{BUN}$, from $0.7 \mathrm{~g}$. per $\mathrm{Kg}$. as moderate to under $10 \mathrm{~g}$. per day as extreme. 